\title{
Ventilatory efficiency in pulmonary vascular diseases
}

\author{
Jason Weatherald (i] ${ }^{1,2}$, Brianne Philipenko ${ }^{1}$, David Montani $\mathbb{1}^{3,4,5}$ and Pierantonio Laveneziana ${ }^{6,7}$ \\ Number 7 in the Series "Ventilatory efficiency and its clinical prognostic value in cardiorespiratory \\ disorders" \\ Edited by Pierantonio Laveneziana and Paolo Palange
}

\begin{abstract}
${ }^{1}$ Dept of Medicine, Division of Respirology, University of Calgary, Cumming School of Medicine, Calgary, Canada. ${ }^{2}$ Libin Cardiovascular Institute, Calgary, Canada. ${ }^{3}$ Faculty of Medicine, Université Paris-Saclay, Le Kremlin-Bicêtre, France. ${ }^{4}$ INSERM UMR_S 999, Pulmonary Hypertension: Pathophysiology and Novel Therapies, Hôpital Marie Lannelongue, Le Plessis-Robinson, France. ${ }^{5}$ Dept of Respiratory and Intensive Care Medicine, Pulmonary Hypertension National Referral Center, Hôpital Bicêtre, Assistance Publique - Hôpitaux de Paris (AP-HP), Le Kremlin-Bicêtre, France. ${ }^{6}$ Sorbonne Université, INSERM, UMRS1158 Neurophysiologie respiratoire expérimentale et clinique, Paris, France. ${ }^{7} \mathrm{AP}-\mathrm{HP}$, Groupe Hospitalier Universitaire APHP-Sorbonne Université, Hôpitaux Pitié-Salpêtrière, Saint-Antoine et Tenon, Service des Explorations Fonctionnelles de la Respiration, de l'Exercice et de la Dyspnée (Département R3S), Paris, France.
\end{abstract}

Corresponding author: Pierantonio Laveneziana (pierantonio.laveneziana@aphp.fr)

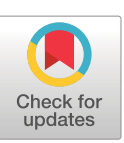

Copyright @ERS 2021

This article is open access and distributed under the terms of the Creative Commons Attribution Non-Commercial Licence 4.0.

Received: 2 July 2020 Accepted: 15 Oct 2020

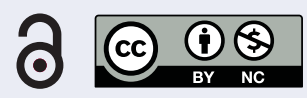

Shareable abstract (@ERSpublications)

Ventilatory inefficiency is a hallmark feature of $\mathrm{PH}$ that reflects abnormal ventilation/perfusion matching, chemosensitivity and an altered $\mathrm{CO}_{2}$ set-point. Minute ventilation $/ \mathrm{CO}_{2}$ production is useful in the diagnosis, management and prognostication of $\mathrm{PH}$. https://bit.ly/3jnNdUG

Cite this article as: Weatherald J, Philipenko B, Montani D, et al. Ventilatory efficiency in pulmonary vascular diseases. Eur Respir Rev 2021; 30: 200214 [DOI: 10.1183/16000617.0214-2020].

\section{Abstract}

Cardiopulmonary exercise testing (CPET) is a frequently used tool in the differential diagnosis of dyspnoea. Ventilatory inefficiency, defined as high minute ventilation $\left(V_{E}^{\prime}\right)$ relative to carbon dioxide output $\left(V^{\prime} \mathrm{CO}_{2}\right)$, is a hallmark characteristic of pulmonary vascular diseases, which contributes to exercise intolerance and disability in these patients. The mechanisms of ventilatory inefficiency are multiple and include high physiologic dead space, abnormal chemosensitivity and an altered carbon dioxide $\left(\mathrm{CO}_{2}\right)$ setpoint. A normal $V^{\prime}{ }_{\mathrm{E}} / V^{\prime} \mathrm{CO}_{2}$ makes a pulmonary vascular disease such as pulmonary arterial hypertension (PAH) or chronic thromboembolic pulmonary hypertension (CTEPH) unlikely. The finding of high $V_{\mathrm{E}}^{\prime} / V^{\prime} \mathrm{CO}_{2}$ without an alternative explanation should prompt further diagnostic testing to exclude PAH or CTEPH, particularly in patients with risk factors, such as prior venous thromboembolism, systemic sclerosis or a family history of PAH. In patients with established $\mathrm{PAH}$ or $\mathrm{CTEPH}$, the $V_{\mathrm{E}}^{\prime} / V^{\prime} \mathrm{CO}_{2}$ may improve with interventions and is a prognostic marker. However, further studies are needed to clarify the added value of assessing ventilatory inefficiency in the longitudinal follow-up of patients.

\section{Introduction}

Pulmonary arterial hypertension (PAH) and chronic thromboembolic pulmonary hypertension (CTEPH) are pulmonary vascular diseases that cause pulmonary hypertension ( $\mathrm{PH}$ ) (table 1). Both are characterised by a pre-capillary pattern of $\mathrm{PH}$ during right heart catheterisation (RHC), which is defined as an elevation in mean pulmonary arterial pressure (mPAP) $>20 \mathrm{mmHg}$, elevation in the pulmonary vascular resistance (PVR) $\geqslant 3$ Wood units, and a normal pulmonary artery wedge pressure (PAWP) $\leqslant 15 \mathrm{mmHg}$ [1]. In PAH, abnormal proliferation, remodelling and rarefaction of the small pulmonary arteries leads to elevation in PVR, high pulmonary arterial pressure and right ventricular dysfunction [2, 3]. CTEPH occurs in about 3\% of patients after pulmonary embolism (PE) $[4,5]$ as a result of persistent organised thrombus in the main, lobar, and/or segmental pulmonary arteries, and there can also be a more distal small vessel disease that resembles PAH [4].

Cardiopulmonary exercise testing (CPET) is a safe and noninvasive tool that can alert the clinician to the possibility of underlying pulmonary vascular disease, elucidate the mechanism of exertional dyspnoea in patients with known PAH or CTEPH, assess disease severity and prognosis and monitor response to 
TABLE 1 Clinical classification of pulmonary hypertension (PH)

$1 \mathrm{PAH}$

Idiopathic PAH

Heritable PAH

Drug- and toxin-induced PAH

$\mathrm{PAH}$ associated with:

Connective tissue disease

HIV infection

Portal hypertension

Congenital heart disease

Schistosomiasis

$\mathrm{PAH}$ long-term responders to calcium channel blockers

$\mathrm{PAH}$ with overt features of venous/capillaries (PVOD/PCH) involvement

Persistent PH of the newborn syndrome

$2 \mathrm{PH}$ due to left heart disease

$\mathrm{PH}$ due to heart failure with preserved LVEF

$\mathrm{PH}$ due to heart failure with reduced LVEF

Valvular heart disease

Congenital/acquired cardiovascular conditions leading to post-capillary PH

$3 \mathrm{PH}$ due to lung diseases and/or hypoxia

Obstructive lung disease

Restrictive lung disease

Other lung disease with mixed restrictive/obstructive pattern

Hypoxia without lung disease

Developmental lung disorders

$4 \mathrm{PH}$ due to pulmonary artery obstructions

Chronic thromboembolic $\mathrm{PH}$

Other pulmonary artery obstructions

$5 \mathrm{PH}$ with unclear and/or multifactorial mechanisms

Haematological disorders

Systemic and metabolic disorders

Others

Complex congenital heart disease

PAH: pulmonary arterial hypertension; PVOD: pulmonary veno-occlusive disease; $\mathrm{PCH}$ : pulmonary capillary haemangiomatosis; LVEF: left ventricular ejection fraction.

treatment [6-8]. Among the many valuable variables acquired during CPET, the peak oxygen consumption $\left(V_{\mathrm{O}_{2}}^{\prime}\right.$ peak) and the ventilatory equivalent for carbon dioxide $\left(V_{\mathrm{E}}^{\prime} / V^{\prime} \mathrm{CO}_{2}\right)$ have been the most widely studied in cardiopulmonary diseases. During exercise, patients with pulmonary vascular disease can exhibit a range of pathological responses that include impaired cardiac output, reduced aerobic capacity, inefficient ventilation (high $V_{E}^{\prime} / V^{\prime} \mathrm{CO}_{2}$ ), hypoxaemia, dynamic hyperinflation, dyspnoea and peripheral muscle dysfunction (figure 1). The objectives of this article are to: 1) review the mechanisms leading to an excessive ventilatory response, or high $V_{\mathrm{E}}^{\prime} / V^{\prime} \mathrm{CO}_{2}$, in PAH and CTEPH; and 2) to review the utility of $V^{\prime}{ }_{\mathrm{E}}^{\prime}$ $V^{\prime} \mathrm{CO}_{2}$ in the diagnosis, prognostication and assessment of treatment response in patients with pulmonary vascular diseases.

What factors determine the $V^{\prime}{ }_{\mathrm{E}} / V^{\prime} \mathrm{CO}_{2}$ ?

The ventilatory response to exercise $\left(V_{\mathrm{E}}^{\prime}\right)$ is closely linked to three variables in Equation 1 and figure 2: $V^{\prime} \mathrm{CO}_{2}$, the arterial partial pressure of carbon dioxide $\left(P_{\mathrm{aCO}_{2}}\right)$, and the physiologic dead space fraction $\left(V_{\mathrm{D}} / V_{\mathrm{T}}\right)$.

$$
V_{E}^{\prime}=\frac{\mathrm{k} \times V^{\prime} \mathrm{CO}_{2}}{P_{\mathrm{aCO}_{2}} \times\left(1-\frac{V_{\mathrm{D}}}{V_{\mathrm{T}}}\right)}
$$

In Equation 1, $\mathrm{k}=863$ is a constant that corrects for the different conditions of reporting gas volumes (standard temperature and pressure, dry; body temperature and pressure, saturated) and transformation of fractional concentration to partial pressure, at a body temperature of $310 \mathrm{~K}$, and a barometric pressure of $760 \mathrm{mmHg}$. 


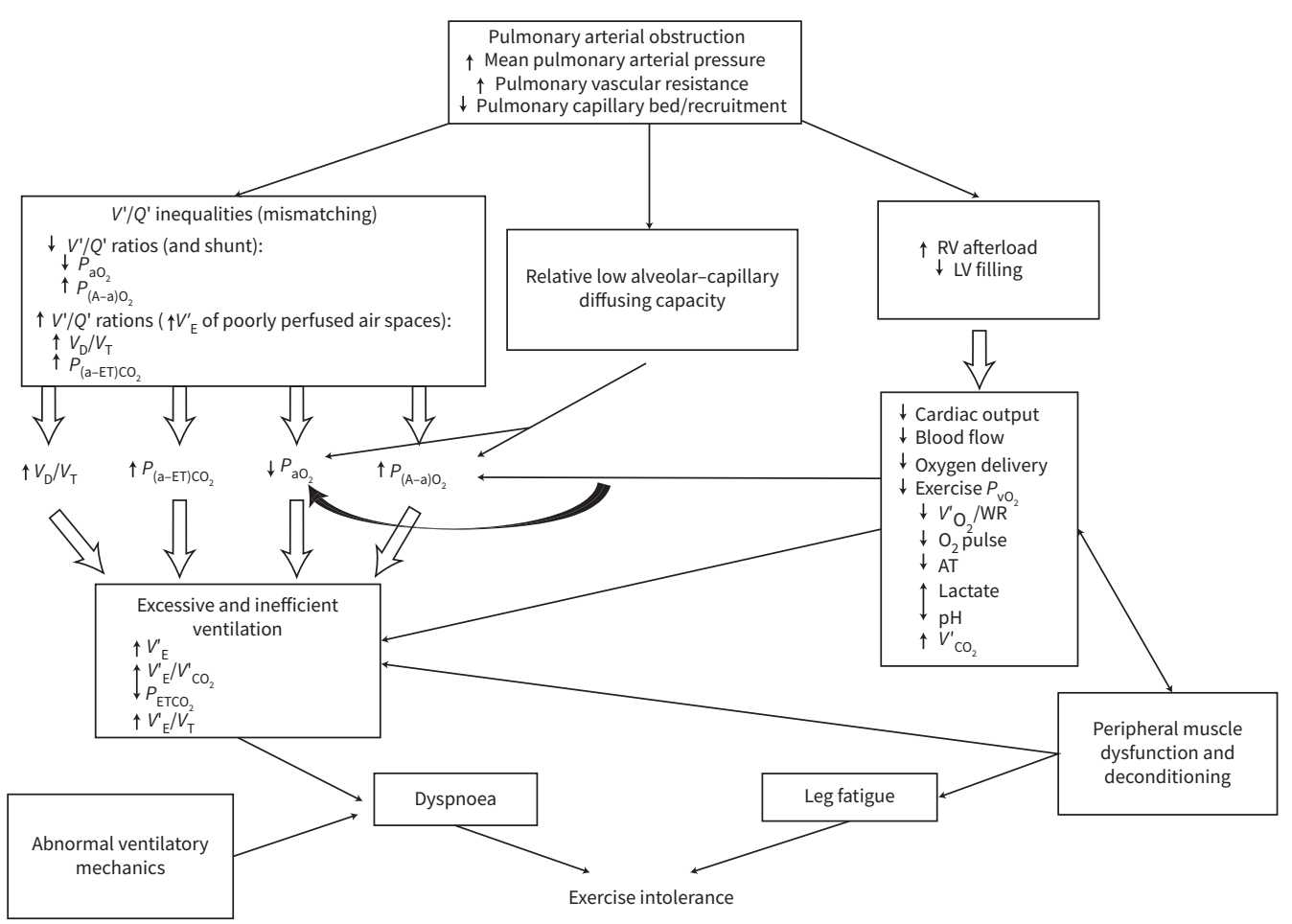

FIGURE 1 Pathophysiology and mechanisms of exercise intolerance in pulmonary hypertension. Pulmonary vascular obstruction results in high ventilation/perfusion ratios $\left(V^{\prime} / Q^{\prime}\right)$, impaired cardiac output and can result in hypoxaemia due to right-to-left shunting through a patent foramen ovale. Inefficient ventilation proposes high ventilatory demand, high minute ventilation $\left(V_{E}^{\prime}\right) /$ carbon dioxide production $\left(V^{\prime} \mathrm{CO}_{2}\right)$ and dead space $\left(V_{\mathrm{D}}\right) /$ tidal volume $\left(V_{\mathrm{T}}\right)$ and low end-tidal carbon dioxide tension $\left(P_{\mathrm{ETCO}}\right)$. Cardiac limitation and peripheral muscle abnormalities result in a low anaerobic threshold (AT), early onset lactic acidosis and increased $V^{\prime} \mathrm{CO}_{2}$, which provide further stimulation for excessive ventilation. Ventilatory mechanical constraints on $V_{\mathrm{T}}$ expansion also contribute to dyspnoea during exercise. LV: left ventricle; $\mathrm{O}_{2}$ pulse: oxygen consumption $\left(V^{\prime} \mathrm{O}_{2}\right)$ to heart rate ratio; $P_{\mathrm{aO}}$ : arterial oxygen tension; $P_{\mathrm{vO}_{2}}$ : venous pressure of oxygen; RV: right ventricle; WR: work rate; $P_{\mathrm{A}-\mathrm{aO}_{2}}$ : alveolar-arterial oxygen tension difference; $P_{(\mathrm{a}-\mathrm{ET}) \mathrm{CO}_{2}}$ : end-tidal partial pressure gradient of $\mathrm{CO}_{2}$.

Rearranging Equation 1, the efficiency of ventilation $\left(V^{\prime}{ }_{E} / V^{\prime} \mathrm{CO}_{2}\right)$ can be expressed as being inversely proportional to just two factors: 1) $P_{\mathrm{aCO}_{2}}$ and 2) $\left(1-V_{\mathrm{D}} / V_{\mathrm{T}}\right)$.

$$
\frac{V_{\mathrm{E}}^{\prime}}{V_{\mathrm{CO}_{2}}^{\prime}}=\frac{k}{P_{\mathrm{aCO}_{2}} \times\left(1-\frac{V_{D}}{V_{T}}\right)}
$$

During exercise, $V_{\mathrm{E}}^{\prime}$ increases linearly with $V^{\prime} \mathrm{CO}_{2}$ due to rising metabolic demand, as extensively reviewed in Weatherald et al. [9]. There is often an inflection in the slope of $V^{\prime}{ }_{E} / V^{\prime} \mathrm{CO}_{2}$ at the respiratory compensation point (RCP) where $V_{\mathrm{E}}^{\prime}$ increases disproportionately to $V_{\mathrm{CO}_{2}}^{\prime}$ due to ventilatory drive stimulation from muscle afferent feedback, central command and metabolic acidosis [10]. The $V_{\mathrm{D}} / V_{\mathrm{T}}$ decreases during exercise in healthy individuals as tidal volume $\left(V_{\mathrm{T}}\right)$ increases several fold and to a much greater extent than the small increase in dead space $\left(V_{\mathrm{D}}\right)$. In healthy individuals, the $P_{\mathrm{aCO}}$ remains essentially unchanged during exercise, except at very heavy intensity when hyperventilation after the RCP results in relative hypocapnia $[11,12]$.

Ventilatory efficiency $\left(V_{\mathrm{E}}^{\prime} / V_{\mathrm{CO}_{2}}^{\prime}\right)$ is usually represented in three ways: 1) the slope of $V_{\mathrm{E}}^{\prime}$ versus $V_{\mathrm{CO}_{2}}^{\prime}$ from onset of exercise to the RCP inflection; 2) the ratio of $V^{\prime}{ }_{\mathrm{E}} / V^{\prime} \mathrm{CO}_{2}$ at the anaerobic threshold (AT); and 3 ) the lowest value (nadir) of the $V_{\mathrm{E}}^{\prime} / V^{\prime} \mathrm{CO}_{2}$ ratio during exercise [13]. The $V_{\mathrm{E}}^{\prime} / V^{\prime} \mathrm{CO}_{2}$ nadir may be the preferred measure of ventilatory efficiency as there is less variability than $V_{E}^{\prime} / V^{\prime} \mathrm{CO}_{2}$ slope and because the AT may not be evident in all individuals [13]. In healthy individuals, the $V^{\prime} / V^{\prime} \mathrm{CO}_{2}$ increases with age and tends to be lower in males than females for any given age [13, 14]. 
Mechanics of breathing: $V_{T}$, respiratory rate, vital capacity

Expiratory flow-limitation $\rightarrow$ dynamic hyperinflation

$\uparrow$ Ventilatory muscle mechanical loading

Mechanical constraints on $V_{T}$ expansion

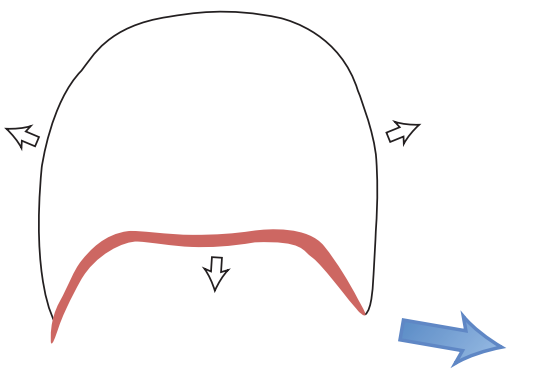

$$
V_{\mathrm{E}}^{\prime}=\frac{863^{*} V^{\prime} \mathrm{CO}_{2}}{P_{\mathrm{aCO}}{ }^{*}\left(1-V_{\mathrm{D}} / V_{\mathrm{T}}\right)}
$$

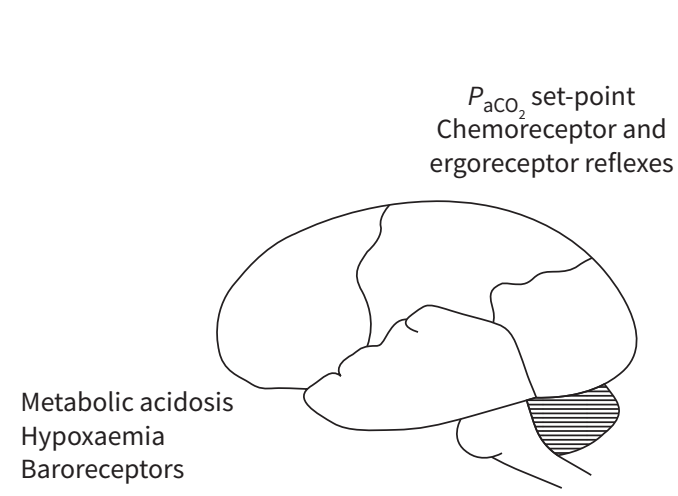

$\sum \sqrt{ }$

$<$

Deconditioning

Skeletal muscle dysfunction

Anaerobic (lactate) threshold

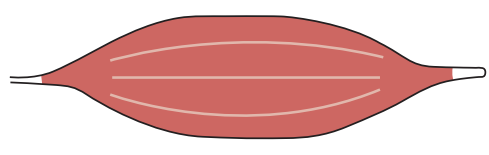

Metabolic demand

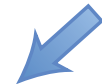

FIGURE 2 Minute ventilation $\left(V_{\mathrm{E}}^{\prime}\right)$ is determined by carbon dioxide production $\left(V_{\mathrm{CO}_{2}}^{\prime}\right)$, the arterial partial pressure of $\mathrm{CO}_{2}\left(P_{\mathrm{acO}}\right)$ and the physiologic dead space to tidal volume $\left(V_{\mathrm{D}} / V_{\mathrm{T}}\right)$. In addition to gas exchange impairment ventilation/perfusion $\left(V^{\prime} / Q^{\prime}\right)$ abnormalities and shunt, mechanical, metabolic and autonomic nervous system reflexes influence these variables to determine the ventilatory demand and ventilatory efficiency. RR: respiratory rate. Reproduced and modified from [9] with permission.

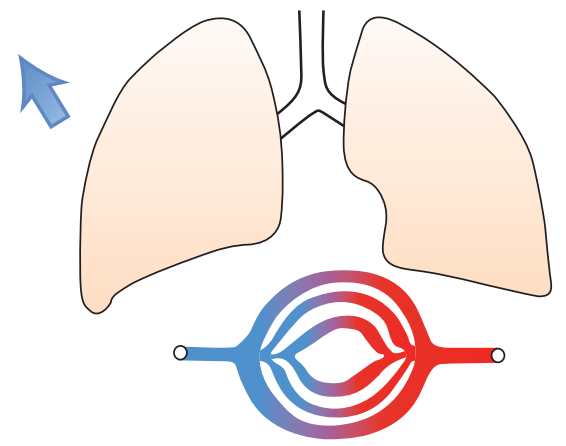

$V^{\prime} / Q^{\prime}$ inequality

Breathing patterns $\left(V_{\mathrm{T}}\right.$ and RR) 
What are the mechanisms of ventilatory inefficiency in pulmonary vascular diseases?

There are several potential mechanisms of high $V^{\prime}{ }_{E} / V^{\prime} \mathrm{CO}_{2}$ in pulmonary vascular disease [9, 15]. First, obstruction and loss of pulmonary vasculature results in heterogeneity in the matching of regional ventilation $\left(V^{\prime}\right)$ and perfusion $\left(Q^{\prime}\right)$, which leads to a higher $V_{\mathrm{D}} / V_{\mathrm{T}}$ [16-18]. Consequently, the efficiency of gas exchange is impaired, resulting in a higher ventilatory demand for a given $V_{\mathrm{CO}_{2}}^{\prime}$ and $P_{\mathrm{aCO}}$. While hypoxaemia is common in PAH and CTEPH and is related to the degree of ventilation-perfusion inequality in the lungs, it does not appear to be a major cause of high $V_{\mathrm{E}}^{\prime} / V^{\prime} \mathrm{CO}_{2}$ in PAH. This was shown by THEODORE and colleagues who evaluated the $V_{E}^{\prime} / V^{\prime}{ }_{\mathrm{CO}_{2}}$ slope before and after heart-lung transplantation [19]. They demonstrated that heart-lung transplantation resulted in a marked decrease in $V_{\mathrm{E}}^{\prime} / V_{\mathrm{CO}_{2}}^{\prime}$ slope from $57.7 \pm 6.8$

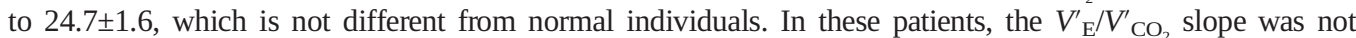
related to resting or exercise levels of the arterial partial pressure of oxygen $\left(P_{\mathrm{aO}_{2}}\right), P_{\mathrm{aCO}_{2}}$ or arterial $\mathrm{pH}$. In another study, Ting et al. infused epoprostenol, a potent pulmonary arterial vasodilator, and observed acute improvements in haemodynamics and $V_{\mathrm{D}} / V_{\mathrm{T}}$ with a decrease in resting $V_{\mathrm{E}}^{\prime} / V^{\prime} \mathrm{CO}_{2}$ from baseline [20]. There were no acute changes in $P_{\mathrm{aO}}, P_{\mathrm{aCO}_{2}}$ or arterial $\mathrm{pH}$. These studies implicated abnormal neurophysiologic and/or haemodynamic mechanisms, rather than deranged blood gases, in the pathophysiology of high $V^{\prime}{ }_{E} / V^{\prime} \mathrm{CO}_{2}$ in patients with pulmonary vascular disease.

Re-examining Equation 2, it is clear that $V_{\mathrm{E}}^{\prime} / V^{\prime} \mathrm{CO}_{2}$ will also be higher if the $P_{\mathrm{aCO}}$ is lower. Several studies have noted that many patients with PAH and CTEPH are hypocapnic at rest [21-24], which cannot be explained by high $V_{\mathrm{D}} / V_{\mathrm{T}}$. Instead, resting hypocapnia is related to abnormal chemoreflexes due to autonomic nervous system dysfunction and/or an altered $P_{\mathrm{aCO}}$ set-point [25]. Most of the available data on autonomic function is from patients with $\mathrm{PAH}$, demonstrating increased sympathetic nervous system activation as measured by muscle sympathetic nerve activity (MSNA) using microneurography [26, 27]. Higher MSNA is associated with worse disease severity and clinical deterioration in PAH [28]. However, the mechanisms of sympathetic activation in PAH have not been fully elucidated. Some studies have shown that noninvasive markers of sympathetic function, such as heart rate variability and baroreflex sensitivity, are impaired in patients with PAH and are related to exercise capacity but not correlated with $V^{\prime}{ }_{E} / V^{\prime} \mathrm{CO}_{2}$ [29]. However, other indirect indicators of sympathetic function during exercise, such as chronotropic response and heart rate recovery after exercise, are correlated to $V_{E}^{\prime} / V^{\prime} \mathrm{CO}_{2}$ in $\mathrm{PAH}$ [30]. In severe PAH and CTEPH, pressure overload leads to right ventricular (RV) dysfunction and an increase in right atrial pressure (RAP), which may directly activate the sympathetic nervous system. Elevated RAP leads to right atrial distention, which may be an important mechanism of sympathetic activation. Decreases in RAP after palliative atrial septostomy correlated with changes in MSNA [31]. This could be a potential overarching explanation for the link between autonomic dysfunction, elevated RAP and prognosis in PAH [32]. Elevated RAP is often seen in patients with severe PAH and CTEPH with RV dysfunction and volume overload. It is important to note that different mechanisms of high $V_{\mathrm{E}}^{\prime} / V_{\mathrm{CO}_{2}}^{\prime}$ may predominate in PAH patients versus CTEPH patients. For example, right ventricular dysfunction may occur in PAH and CTEPH, but echocardiographic measures of RV dysfunction were only correlated with exercise capacity and $V^{\prime}{ }_{E} / V^{\prime} \mathrm{CO}_{2}$ in patients with PAH, not patients with CTEPH [33]. In CTEPH, exercise capacity and $V^{\prime}{ }_{\mathrm{E}} /$ $V^{\prime} \mathrm{CO}_{2}$ may be less determined by haemodynamics, RV function or autonomic hyperactivity but predominantly determined by the degree of pulmonary vascular obstruction and the $V_{\mathrm{D}} / V_{\mathrm{T}}[34,35]$.

Two recent studies support the importance of abnormal chemoreflexes and a lower $P_{\mathrm{acO}}$ set-point in the inefficient ventilation observed in pulmonary vascular diseases. Our group recently demonstrated that the maximal value of end-tidal partial pressure of $\mathrm{CO}_{2}\left(P_{\mathrm{ETCO}_{2}}\right)$ between the AT and RCP, an indicator of the $P_{\mathrm{aCO}_{2}}$ set-point, was significantly lower in hypocapnic patients with PAH, CTEPH, and pulmonary veno-occlusive disease [22]. In a broad group of patients with pulmonary vascular disease, maximal $P_{\mathrm{ETCO}_{2}}$ was a stronger correlate of peak $V_{\mathrm{O}_{2}}^{\prime}(\mathrm{r}=0.64)$ and $V_{\mathrm{E}}^{\prime} / V_{\mathrm{CO}_{2}}^{\prime}$ slope $(\mathrm{r}=-0.86)$ than $P_{\mathrm{aCO}}$ or $V_{\mathrm{D}} / V_{\mathrm{T}}$. This suggests that an altered $P_{\mathrm{aCO}}$ set-point is an important determinant of exercise capacity and ventilatory inefficiency in pulmonary vascular disease. FARINA et al. used hypoxic and hypercapnic challenge testing to test the role of peripheral and central chemoreflexes in PAH $(n=16)$ [24]. Peripheral chemoreflex responses to hypoxia and hypercapnia and the central hypercapnic chemosensitivity reflex were all increased compared with healthy individuals. The peripheral reflexes were not related to any exercise variables; however, the central hypercapnic response was correlated with the alveolar ventilation $\left(V_{\mathrm{A}}^{\prime}\right)$ to $V_{\mathrm{CO}_{2}}^{\prime}$ slope $(\mathrm{r}=0.65)$, indicating that overactive central autonomic $\mathrm{CO}_{2}$ chemoreflexes are an important contributor to exercise hyperventilation in PAH [24].

Dynamic hyperinflation results in mechanical limitation to $V_{\mathrm{T}}$ expansion during exercise and can limit the rise in $V_{\mathrm{E}}^{\prime}$ relative to $V_{\mathrm{CO}_{2}}^{\prime}$ in patients with COPD [36, 37]. Interestingly, dynamic hyperinflation occurs in up to $60 \%$ of $\mathrm{PAH}$ and CTEPH patients in the absence of smoking or overt airflow obstruction, which increases dyspnoea for a given $V_{\mathrm{E}}^{\prime}$ [23]. Although the mechanisms of dynamic hyperinflation in pulmonary 

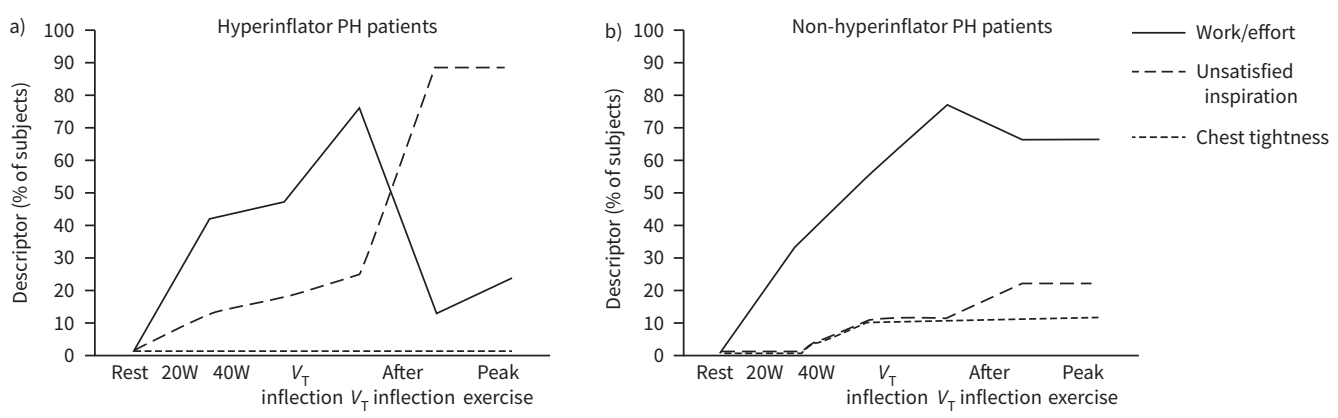

FIGURE 3 a) Selection frequency of the three descriptor phrases evaluated during symptom-limited incremental cycle exercise in patients with pulmonary hypertension (PH) who hyperinflate (hyperinflators) during exercise: increased work/effort, unsatisfied inspiration and chest tightness. Data are presented as mean at rest, at $20 \mathrm{~W}$ (iso-WR 1), at $40 \mathrm{~W}$ (iso-WR 2), at the tidal volume $\left(V_{\mathrm{T}}\right)$ inflection point, after the $V_{\mathrm{T}}$ inflection point and at peak exercise. b) Selection frequency of the three descriptor phrases evaluated during symptom-limited incremental cycle exercise in patients with $\mathrm{PH}$ who deflate (nonhyperinflators) during exercise: increased work/effort, unsatisfied inspiration and chest tightness. Data are presented as mean at rest, at $20 \mathrm{~W}$ (iso-WR 1), at $40 \mathrm{~W}$ (iso-WR 2), at the $V_{\mathrm{T}}$ inflection point, after the $V_{\mathrm{T}}$ inflection point and at peak exercise. Reproduced and modified from [38] with permission.

vascular disease are not exactly known, our group recently demonstrated that patients with PAH and CTEPH who develop dynamic hyperinflation during exercise have a lower $V^{\prime}{ }_{\mathrm{E}} / V^{\prime} \mathrm{CO}_{2}$ slope than those who did not develop dynamic hyperinflation [38]. Dyspnoea perception in these hyperinflators was more related to "air hunger” and unsatisfied inspiration, likely related to the mechanical constraint on $V_{\mathrm{T}}$ (figure 3 ). In contrast, descriptors of "breathing a lot" and increased work/effort predominated in nonhyperinflators who had higher $V_{\mathrm{E}}^{\prime}$ and higher $V_{\mathrm{E}}^{\prime} / V^{\prime} \mathrm{CO}_{2}$. This study illustrates the complex relationships between respiratory mechanics and ventilatory inefficiency in PAH and CTEPH.

Is ventilatory inefficiency useful in the diagnosis of pulmonary hypertension?

Ventilatory inefficiency is not unique to pulmonary vascular disease but is a hallmark feature, as demonstrated in a seminal paper by Sun et al. [39]. Both $V_{\mathrm{E}}^{\prime} / V^{\prime} \mathrm{CO}_{2}$ slope and $V_{\mathrm{E}}^{\prime} / V^{\prime} \mathrm{CO}_{2}$ at AT correlated with disease severity as measured by New York Heart Association (NYHA) functional class, although peak $V_{\mathrm{O}_{2}}^{\prime}$ was more strongly related to NYHA class and haemodynamic severity. In patients with mild $\mathrm{PAH}, V_{\mathrm{E}}^{\prime} / V_{\mathrm{CO}_{2}}^{\prime}$ was significantly higher than normal controls, suggesting that ventilatory inefficiency could be a useful marker of early disease [39]. As such, a normal $V^{\prime}{ }_{E} / V^{\prime} \mathrm{CO}_{2}$ makes pulmonary vascular disease unlikely and an invasive investigation, such as RHC, is not usually warranted in this situation unless other clinical data point strongly towards $\mathrm{PH}$. In contrast, high $V_{\mathrm{E}}^{\prime} / V^{\prime} \mathrm{CO}_{2}$ is not specific to pulmonary vascular disease but warrants further investigation for $\mathrm{PH}$ when present, especially in the absence of other causes (e.g. parenchymal lung disease, heart failure).

In patients with systemic sclerosis (SSc), who are at risk of developing PAH, CPET may have a role in screening. Elevated $V_{\mathrm{E}}^{\prime} / V^{\prime} \mathrm{CO}_{2}$ in a patient with SSc suggests underlying pulmonary vascular disease and should prompt further testing. This was illustrated in a prospective study of 173 patients with SSc without known PAH who underwent CPET and RHC, in which $V^{\prime} / V^{\prime} \mathrm{CO}_{2}$ was significantly higher in patients who were ultimately diagnosed with PAH $(\mathrm{n}=48)$ compared with those with normal haemodynamics $(\mathrm{n}=115)$ or post-capillary $\mathrm{PH}(\mathrm{n}=10)$. The $V_{\mathrm{E}}^{\prime} / V^{\prime} \mathrm{CO}_{2}$ nadir correlated with mean pulmonary arterial pressure (rho=0.61), PVR (rho=0.58) and accurately discriminated patients who had PAH (area under the curve (AUC) 0.85 , 95\% CI 0.77-0.92) [40]. Using a threshold of $V^{\prime}{ }_{\mathrm{E}} / V^{\prime} \mathrm{CO}_{2}$ nadir of 27.8 had $95.8 \%$ sensitivity and 25\% specificity for detecting $\mathrm{PAH}$, whereas at an "optimal” threshold of 35.5, the $V_{\mathrm{E}}^{\prime} / V^{\prime} \mathrm{CO}_{2}$ nadir had $79.2 \%$ sensitivity and $82.9 \%$ specificity. $\mathrm{A} V_{\mathrm{E}}^{\prime} / V^{\prime} \mathrm{CO}_{2}$ nadir $>45.5$ effectively ruled-in $\mathrm{PAH}$ with a positive predictive value of $100 \%$. Currently, many patients with SSc are screened for PAH using the DETECT algorithm which uses clinical, laboratory, and echocardiographic variables to determine the need for RHC [41]. A recent study demonstrated that $V^{\prime}{ }_{E} / V^{\prime} \mathrm{CO}_{2}$ may have additive value to the DETECT algorithm by helping to reduce the number of unnecessary invasive RHCs [42]. In 54 SSc patients who screened positive using the DETECT algorithm and underwent CPET and RHC, 17 patients (31\%) had PAH which

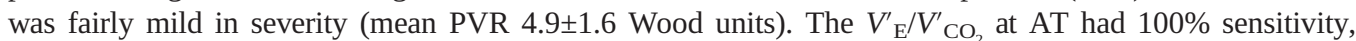
$83 \%$ specificity, $70 \%$ positive predictive value, and $100 \%$ negative predictive value for identifying $\mathrm{PAH}$, with similar performance for the $V^{\prime}{ }_{\mathrm{E}} / V^{\prime} \mathrm{CO}_{2}$ slope (sensitivity $100 \%$, specificity $78 \%$, positive predictive value $63 \%$, negative predictive value $100 \%$ ) [42]. Based on these performance characteristics, a patient with a $V_{\mathrm{E}}^{\prime} / V_{\mathrm{CO}_{2}}^{\prime}$ slope of $<39$ would not need RHC despite screening positive on the DETECT algorithm. 
There are heritable forms of PAH, most commonly due to mutations in the Bone Morphogenic Protein Receptor 2 (BMPR2) gene. Limited data and recent guidelines suggest that asymptomatic mutation carriers should be screened for PAH [43, 44]. CPET is an attractive option for screening asymptomatic carriers since ventilatory abnormalities may be present early in the development of $\mathrm{PAH}$, before echocardiographic changes suggesting PH are seen or when disease features begin to manifest $[45,46]$. The results of the DELPHI-2 study, which used a multimodal screening approach for asymptomatic BMPR2 mutation carriers, suggested that a CPET-derived probability score including the $V^{\prime}{ }_{E} / V^{\prime} \mathrm{CO}_{2}$ can help detect early disease in this at-risk group [47].

The $V_{\mathrm{E}}^{\prime} / V^{\prime} \mathrm{CO}_{2}$ can be useful to distinguish between potential causes of $\mathrm{PH}$. Left heart disease is the most common cause of elevated pulmonary pressure. $V^{\prime}{ }_{E} / V^{\prime} \mathrm{CO}_{2}$ is elevated in patients with heart failure and reduced ejection fraction (HFrEF) $[48,49]$. However, the $V^{\prime}{ }_{E} / V^{\prime} \mathrm{CO}_{2}$ is typically much higher at rest and throughout exercise in patients with pulmonary vascular disease compared with patients with HFrEF of the same functional capacity [50-53]. A more challenging clinical scenario is differentiating PAH from heart failure with preserved ejection fraction (HFpEF) when there is $\mathrm{PH}$ and the left ventricular systolic function is normal on echocardiogram. Most CPET studies in HFpEF patients report mean $V_{\mathrm{E}}^{\prime} / V^{\prime} \mathrm{CO}_{2}$ slope values in the range of 35 to 40 [54-58], which is less than is typically seen in PAH [19, 34, 39, 59]. However, no studies have evaluated the utility of $V_{\mathrm{E}}^{\prime} / V^{\prime} \mathrm{CO}_{2}$ slope to discriminate between PAH and HFpEF in patients matched for a similar degree of $\mathrm{PH}$ or functional impairment. Approximately 22\% of HFpEF patients with $\mathrm{PH}$ also have evidence of pulmonary vascular disease (the combined pre- and post-capillary $\mathrm{PH}$ phenotype), which is associated with higher mean pulmonary pressure and worse RV function than patients with HFpEF and isolated post-capillary $\mathrm{PH}[1,60]$. This likely reflects development of intrinsic pulmonary vascular disease in patients with HFpEF from global vascular remodelling in the pulmonary arteries and veins [61]. In patients with $\mathrm{HFpEF}$ and $\mathrm{PH}$, the $V^{\prime}{ }_{\mathrm{E}} / V^{\prime} \mathrm{CO}_{2}$ correlates with PVR, with higher $V^{\prime}{ }_{E} / V^{\prime} \mathrm{CO}_{2}$ values associated with pulmonary vascular disease and worse outcomes [62]. This is consistent with other studies showing that $V^{\prime}{ }_{\mathrm{E}} / V^{\prime} \mathrm{CO}_{2}$ in patients with $\mathrm{HFpEF}$ is linked more strongly to $V_{\mathrm{D}} / V_{\mathrm{T}}$ $\left(\mathrm{R}^{2}=0.50\right)$ than in patients with $\operatorname{HFrEF}\left(\mathrm{R}^{2}=0.30\right)$ [54].

Although $V^{\prime}{ }_{E} / V^{\prime} \mathrm{CO}_{2}$ is elevated in patients with $\mathrm{PAH}$ and patients with CTEPH, there are important differences between these diseases and $V^{\prime}{ }_{E} / V^{\prime}{ }_{\mathrm{CO}_{2}}$ is often even higher in CTEPH than in PAH (figure 4). ZHAI et al. compared CPET responses between patients with PAH $(\mathrm{n}=77)$ and CTEPH $(\mathrm{n}=50)$ who were similar in terms of functional capacity, 6-min walk distance (6MWD) impairment and haemodynamic severity [34]. In patients with CTEPH, the $V^{\prime}{ }_{E} / V^{\prime} \mathrm{CO}_{2}$ slope was significantly higher compared with patients with PAH (50.7 \pm 15.2 versus $44.4 \pm 15, \mathrm{p}=0.024) . V^{\prime}{ }_{\mathrm{E}} / V^{\prime} \mathrm{CO}_{2}$ at AT was also higher in patients with CTEPH (47.7 \pm 12.6 versus $42.0 \pm 8.5$, $\mathrm{p}=0.008$ ), with higher breathing frequency and $V_{\mathrm{E}}^{\prime}$ at peak exercise in patients with CTEPH despite comparable peak $V_{\mathrm{O}_{2}}^{\prime}$ and peak work rate (WR). The $V_{\mathrm{D}} / V_{\mathrm{T}}$ at peak exercise is also higher in patients with CTEPH compared with patients with PAH [34, 63], possibly due to a relatively greater degree of pulmonary vascular obstruction. AкIzUKi and colleagues recently evaluated whether postural changes in ventilatory parameters could distinguish between PAH and CTEPH in a prospective cohort of 90 patients with suspected $\mathrm{PH}$ [64]. In the sitting position, $V^{\prime}{ }_{\mathrm{E}} / V^{\prime} \mathrm{CO}_{2}$ was similar between $\mathrm{PAH}$, $\mathrm{CTEPH}$ and controls, but $V_{\mathrm{E}}^{\prime} / V^{\prime} \mathrm{CO}_{2}$ decreased in controls and patients with PAH and increased in patients with CTEPH when in the supine position. As such, the positional change in $V_{E}^{\prime}{ }_{E} / V_{\mathrm{CO}_{2}}\left(\Delta V_{\mathrm{E}}^{\prime} / V_{\mathrm{CO}_{2}}^{\prime}\right)$ was positive in CTEPH and negative in PAH and controls. A $\Delta V^{\prime}{ }_{\mathrm{E}} / V^{\prime} \mathrm{CO}_{2}>0.8$ was able to differentiate CTEPH from PAH (AUC=0.849, sensitivity $=78 \%$, specificity=88\%), which may be a useful finding to validate since positional $V_{E}^{\prime} / V^{\prime} \mathrm{CO}_{2}$ is noninvasive and not dependent on patient effort during exercise.

The incidence of CTEPH after acute PE is approximately 3\% [5]; however, routine screening for CTEPH in patients after an acute PE is currently not recommended [65]. In patients who have dyspnoea after PE, CPET and evaluation of ventilatory efficiency may help detect CTEPH. Several studies have shown that elevated $V_{E}^{\prime} / V_{\mathrm{CO}_{2}}^{\prime}$ can help detect CTEPH after acute PE. XI and colleagues compared CPET variables between patients with established $\mathrm{CTEPH}$, chronic $\mathrm{PE}$ without $\mathrm{PH}$, recovered patients with $\mathrm{PE}$ and controls. A $V^{\prime}{ }_{E} / V^{\prime} \mathrm{CO}_{2}$ nadir of $\geqslant 34.35$ was the best predictor of CTEPH (odds ratio 159.0, 95\% CI 36.0 702.3, $\mathrm{p}<0.001$ ) [66]. The $V_{\mathrm{E}}^{\prime} / V^{\prime} \mathrm{CO}_{2}$ was linearly related to the degree of residual pulmonary vascular obstruction on lung perfusion imaging post-acute PE. MCCABE et al. demonstrated that CPET findings can distinguish between patients with CTEPH, chronic thromboembolic disease without PH (CTED) and sedentary controls [67]. Patients with CTEPH had a higher $V^{\prime}{ }_{E} / V_{\mathrm{CO}_{2}}^{\prime}$ slope and higher $V_{\mathrm{E}}^{\prime} / V^{\prime} \mathrm{CO}_{2}$ at AT compared with CTED and control patients. Interestingly, in this study patients with CTEPH also had significantly higher $V_{\mathrm{D}} / V_{\mathrm{T}}$ than patients with CTED despite a similar degree of pulmonary vascular obstruction between patients with CTEPH and patients with CTED. Among the best variables for differentiating from patients with CTEPH from non-CTEPH patients were the peak exercise $V_{\mathrm{D}} / V_{\mathrm{T}}$ (AUC 0.88, 95\% CI 0.67-0.97) and $V^{\prime}{ }^{\prime} / V^{\prime} \mathrm{CO}_{2}$ at AT (AUC=0.77, 95\% CI 0.61-0.92) [67]. 


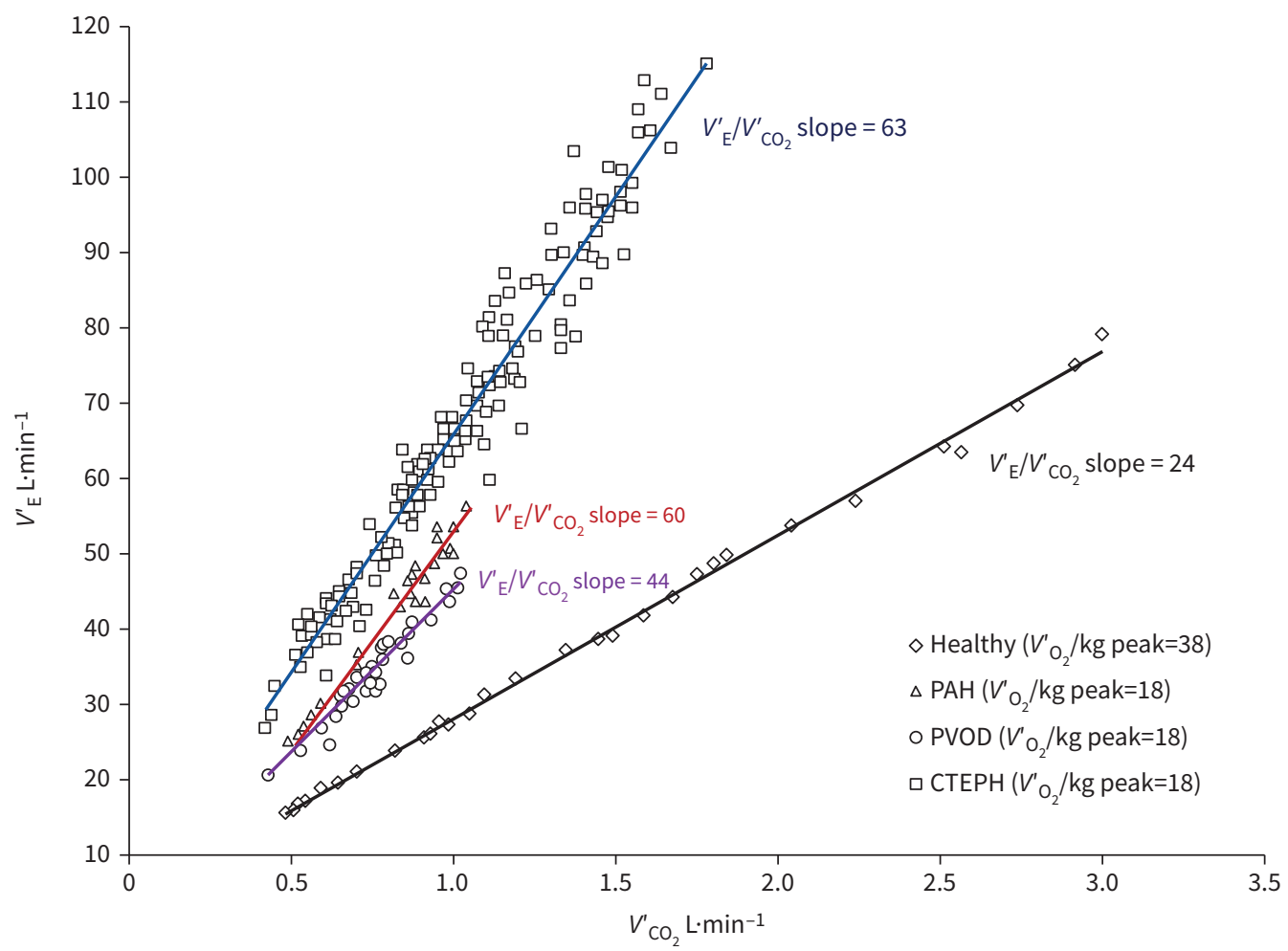

FIGURE 4 Examples of ventilatory efficiency slope (minute ventilation/carbon dioxide production $\left(V^{\prime}{ }_{E} / V^{\prime} \mathrm{CO}_{2}\right)$ slope) in a healthy subject presenting with a peak oxygen uptake $\left(V_{\mathrm{O}_{2}}^{\prime}\right)$ of $38 \mathrm{~mL} \cdot \mathrm{Kg}^{-1} \cdot \mathrm{min}^{-1}$ (black line and rhomboid), a patient with pulmonary veno-occlusive disease (PVOD) presenting with a peak $V_{\mathrm{O}_{2}}^{\prime}$ of $18 \mathrm{~mL} \cdot \mathrm{Kg}^{-1} \cdot \mathrm{min}^{-1}$ (violet line and circles), a patient with pulmonary arterial hypertension (PAH) presenting with a peak $V^{\prime} \mathrm{O}_{2}$ of $18 \mathrm{~mL} \cdot \mathrm{Kg}^{-1} \cdot \mathrm{min}^{-1}$ (red line and triangles) and a patient with chronic thromboembolic pulmonary hypertension (CTEPH) presenting with a peak $V^{\prime}{ }_{\mathrm{O}_{2}}$ of $18 \mathrm{~mL} \cdot \mathrm{Kg}^{-1} \cdot \mathrm{min}^{-1}$ (blue line and squares).

Some symptomatic patients with CTEPH will have normal estimated pulmonary arterial pressure on echocardiography or unmeasurable pressure due to insufficient tricuspid valve regurgitation. HeLD and colleagues evaluated the utility of CPET to detect CTEPH and found that echocardiograms were normal or had undetectable RV systolic pressure in $31 \%$ of patients with confirmed CTEPH [68]. The $V_{E}^{\prime} / V^{\prime} \mathrm{CO}_{2}$ at AT was abnormal in 12/13 (92\%) of patients with CTEPH and normal echocardiography, while the $V^{\prime}{ }_{\mathrm{E}} /$ $V^{\prime} \mathrm{CO}_{2}$ slope was abnormal in 9/13 (69\%).

Pulmonary veno-occlusive disease/pulmonary capillary haemangiomatosis (PVOD/PCH) is a rare condition characterised by a spectrum of pathologic abnormalities of the pulmonary veins and capillaries leading to pre-capillary $\mathrm{PH}$ [69]. It is critically important to differentiate PVOD/PCH from PAH as the former group of patients frequently develop pulmonary oedema when treated with PAH therapies, which can cause rapid deterioration and death $[70,71]$. Limited data suggest that CPET may be useful to identify PVOD/PCH. Compared with stable patients with PAH with similar haemodynamic severity, patients with PVOD/PCH have lower resting and peak exercise $P_{\mathrm{aCO}}$, higher $V_{\mathrm{E}}^{\prime} / V_{\mathrm{CO}_{2}}^{\prime}$ slope and $V_{\mathrm{E}}^{\prime} / V_{\mathrm{CO}_{2}}^{\prime}$ at AT, and higher peak exercise $V_{\mathrm{D}} / V_{\mathrm{T}}[22,72]$.

\section{Is $V^{\prime}{ }_{E} / V^{\prime}{ }_{\mathrm{CO}_{2}}$ responsive to treatment of PAH and CTEPH?}

Treatments for PAH and CTEPH have evolved over the past few decades with major advances leading to improved outcomes. In PAH, current medical therapies target the nitric oxide (NO), endothelin and prostacyclin pathways, resulting in pulmonary arterial vasodilation along with anti-proliferative effects. $\mathrm{PAH}$ therapies that result in acute vasodilation have inconsistent effects on $V_{\mathrm{E}}^{\prime} / V_{\mathrm{CO}_{2}}^{\prime}$ even though haemodynamic improvements may occur immediately. Inhaled NO at $20 \mathrm{ppm}$ during constant WR cycle exercise did not improve $V_{\mathrm{E}}^{\prime} / V^{\prime} \mathrm{CO}_{2}$ or most other exercise parameters in patients with PAH [73]. Short-term infusion of intravenous epoprostenol resulted in decreased $V^{\prime}{ }_{E} / V_{\mathrm{CO}_{2}}^{\prime}$ in six of 10 patients, 
which tended to parallel decreases in total PVR but not changes in mPAP or cardiac index [20]. In a small randomised trial, after 1 week of oral L-arginine (a precursor for NO synthesis) supplementation, the $V^{\prime}{ }_{\mathrm{E}} / V^{\prime} \mathrm{CO}_{2}$ slope decreased from $43 \pm 4$ to $37 \pm 3(\mathrm{p}<0.05)$, along with an increase in peak $V^{\prime} \mathrm{O}_{2}$ from $831 \pm 88$ to $896 \pm 92 \mathrm{~mL} \cdot \mathrm{min}^{-1}(\mathrm{p}<0.05)$ [74]. Similarly, in a mixed population of PAH and CTEPH, 3 months of oral beraprost (a prostacyclin derivative) improved $V^{\prime}{ }_{\mathrm{E}} / V^{\prime} \mathrm{CO}_{2}$ and peak $V_{\mathrm{O}_{2}}^{\prime}$ [75]. These studies suggest that high $V^{\prime}{ }_{E} / V^{\prime} \mathrm{CO}_{2}$ and treatment-related improvements are not driven by acute changes in haemodynamics or ventilation-perfusion but by intermediate- or long-term adaptations in autonomic function. Supporting this hypothesis, administration of hyperoxia to patients with PAH and CTEPH (which does not acutely affect haemodynamics or ventilation-perfusion inequality) during exercise resulted in improved exercise performance and a significant decrease in $V^{\prime}{ }_{E} / V^{\prime}{ }_{\mathrm{CO}_{2}}$ along with improved quadriceps and cerebral tissue oxygenation, whereas the $V_{\mathrm{D}} / V_{\mathrm{T}}$ was unchanged [76].

Patients with CTEPH should be evaluated in expert surgical centres and those patients who are considered operable should undergo pulmonary endarterectomy (PEA) surgery [65, 77]. This surgical procedure removes the chronic, fibrotic material obstructing the pulmonary arteries, immediately reducing mPAP and improving pulmonary blood flow [78]. In a study of 20 patients with CTEPH who underwent PEA surgery, the greatest improvements in $V^{\prime}{ }_{E} / V^{\prime} \mathrm{CO}_{2}$ occurred within 1 month of surgery and continued to decrease by 4 months post-operatively. In contrast, the improvement in peak $V^{\prime} \mathrm{O}_{2}$ was more gradual as observed at 1- and 4-months of follow-up [79]. In this study, the improvements in $V_{\mathrm{E}}^{\prime} / V^{\prime} \mathrm{CO}_{2}$ post-PEA were strongly related to the decrease in PVR, whereas changes in $V_{\mathrm{O}_{2}}^{\prime}$ were not related to PVR improvements. This suggests that: 1) $V_{\mathrm{O}_{2}}^{\prime}$ improvements are more due to peripheral skeletal muscle adaptation from increased activity; and 2) $V_{E}^{\prime} / V^{\prime} \mathrm{CO}_{2}$ may be a better and earlier noninvasive measure of surgical success.

CTED is defined as persistent obstruction of the pulmonary arteries without $\mathrm{PH}$ at rest. Although $\mathrm{PH}$ is absent at rest, patients with CTED often have abnormal haemodynamic responses to exercise and may have reduced exercise tolerance and/or experience exertional dyspnoea as a result of exercise-induced $\mathrm{PH}$ and ventilatory inefficiency [80, 81]. Interestingly, PEA is performed in some centres for CTED, and can significantly improve exercise haemodynamics, peak $V^{\prime}{ }_{\mathrm{O}_{2}}, V^{\prime}{ }_{\mathrm{E}} / V^{\prime} \mathrm{CO}_{2}$ and quality of life [80, 81].

Balloon pulmonary angioplasty (BPA) is a treatment option for patients with CTEPH or CTED which involves catheter-based angioplasty in the segmental and subsegmental pulmonary arteries [82]. BPA can be considered for patients with CTEPH or CTED who are not operable or who have residual disease after PEA. Several studies have demonstrated that BPA improves haemodynamics and improves ventilatory efficiency [83-87] especially when performed in the lower lung zones, presumably due to relatively larger improvements in $V_{\mathrm{A}}^{\prime} / Q^{\prime}$ matching when lower lobe obstruction is present [85]. Interestingly, exercise rehabilitation after BPA further improves $V_{\mathrm{O}_{2}}^{\prime}$ but has no effect on $V_{\mathrm{E}}^{\prime} / V^{\prime} \mathrm{CO}_{2}$ [88]. This reinforces the concept that $V_{\mathrm{O}_{2}}^{\prime}$ improvements after interventions for CTEPH and CTED include cardiopulmonary and peripheral adaptation, whereas improvements in ventilatory efficiency are primarily driven by improved pulmonary blood flow (reduced PVR and improved $V_{\mathrm{A}}^{\prime} / Q^{\prime}$ matching).

\section{What is the prognostic utility of ventilatory efficiency in PAH and CTEPH?}

Risk assessment is an essential component of routine care in PAH and CTEPH. A multifaceted approach is recommended by the European Society of Cardiology/European Respiratory Society (ESC/ERS) guidelines including assessment of clinical symptoms, functional capacity, RV function and exercise capacity [65]. Ideally, a risk assessment tool should be noninvasive, independently associated with an outcome of interest, sensitive to change from treatment effects, widely available and reproducible. In the 2015 ESC/ ERS guidelines, CPET is included as on option to assess prognosis, with $V_{\mathrm{O}_{2}}^{\prime}$ and $V_{\mathrm{E}}^{\prime} / V^{\prime} \mathrm{CO}_{2}$ slope present in the risk assessment table tool as an alternative to 6MWD. When available, CPET is recommended for younger, more fit patients since the threshold on a 6MWD $>440$ m may be more easily achieved compared with older patients [65]. But how strong is the data to support the use of $V^{\prime}{ }_{E} / V_{\mathrm{CO}_{2}}^{\prime}$ as a tool in risk assessment?

$V_{\mathrm{E}}^{\prime} / V^{\prime} \mathrm{CO}_{2}$ has been assessed as a prognostic variable on its own and in conjunction with other standard tools used for risk assessment. Both $V_{\mathrm{E}}^{\prime} / V^{\prime} \mathrm{CO}_{2}$ slope and $V_{\mathrm{E}}^{\prime} / V^{\prime} \mathrm{CO}_{2}$ at $\mathrm{AT}$ have been associated with survival. Schwaiblmair et al. demonstrated in a mixed PAH $(\mathrm{n}=85)$ and CTEPH $(\mathrm{n}=31)$ population that $V_{\mathrm{E}}^{\prime} / V^{\prime} \mathrm{CO}_{2}$ was much higher in nonsurvivors than survivors over a 24-month period [89]. $\mathrm{A} V_{\mathrm{E}}^{\prime} / V^{\prime} \mathrm{CO}_{2}$ at $\mathrm{AT}$ $>55$ was associated with a 7.8 -fold relative risk of death at 2 years while a $V^{\prime}{ }_{\mathrm{E}} / V^{\prime} \mathrm{CO}_{2}$ slope $\geqslant 60$ had a relative risk of 5.75. In this study, $V_{\mathrm{O}_{2}}^{\prime}$ was not associated with outcomes. Because of the smaller number of patients with CTEPH included this study, groups were not split by aetiology to assess the prognostic value of $V^{\prime}{ }_{\mathrm{E}} / V_{\mathrm{CO}_{2}}^{\prime}$ independently in each disease [89]. Wensel et al. also showed $V_{\mathrm{E}}^{\prime} / V^{\prime} \mathrm{CO}_{2}$ slope was 
associated with survival in 70 patients with $\mathrm{PAH}$ using univariate analysis [59]. However, peak $V^{\prime} \mathrm{O}_{2}$ was the only CPET variable independently associated with outcomes in multivariable analysis. OuDIz et al. also reported a hazard ratio of 1.48 for each unit increase in the $V^{\prime}{ }^{\prime} / V^{\prime} \mathrm{CO}_{2}$ at $\mathrm{AT}$, with a mean value of 54.2 in the nonsurvivor group. Also demonstrated in this study is the prognostic significance of detecting an exercise-induced shunt through a patent foramen ovale during CPET testing, for which an abrupt increase in $V^{\prime}{ }_{\mathrm{E}} / V^{\prime} \mathrm{CO}_{2}$ was used as a diagnostic criteria [90].

$V^{\prime}{ }_{\mathrm{E}} / V^{\prime} \mathrm{CO}_{2}$ has also been assessed in PAH associated with other conditions. DeBoeck et al. reported on patients with idiopathic PAH and patients with PAH associated with other conditions. They found that in idiopathic $\mathrm{PAH}, \mathrm{V}_{\mathrm{E}}^{\prime} / \mathrm{V}^{\prime} \mathrm{CO}_{2}$ at AT cut-offs of 54 and 59 were predictive of survival and time to clinical worsening respectively, while in patients with $\mathrm{PAH}$ associated with other conditions, no variables were predictive [91]. This may be due to the heterogeneity of underlying diseases in their "associated-PAH group”, as it included patients with connective tissue disease, hepatic cirrhosis, human immunodeficiency virus or schistosomiasis. A retrospective study looked at patients with systemic sclerosis, with or without a diagnosis of $\mathrm{PAH}$, and showed a $V_{\mathrm{E}}^{\prime} / V^{\prime} \mathrm{CO}_{2}$ slope cut-off of 35 predictive of survival in multivariate analysis. Due to limited numbers, however, they were unable to separately analyse the PAH patients [92]. $V^{\prime}{ }_{E} / V^{\prime} \mathrm{CO}_{2}$ slope was also shown to be predictive of mortality in adult congenital heart disease patients, with the highest slopes being in the Eisenmenger population $(71.2 \pm 24.6)$ and the idiopathic pulmonary arterial hypertension population (51.6 \pm 15$)$ [93].

FERREIRA et al. demonstrated improved prognostic value of $V_{E}^{\prime} / V^{\prime} \mathrm{CO}_{2}$ slope when taken at maximal exercise $\left(V_{\mathrm{E}}^{\prime} / V^{\prime} \mathrm{CO}_{2}\right.$ peak), although the utility of this approach is limited by the patients' ability to reach a maximal effort [94]. Despite this, CPET variables can still be useful even in cases with submaximal effort. Since $V^{\prime}{ }_{E} / V^{\prime} \mathrm{CO}_{2}$ slope calculation does not require that a patient achieves peak effort, the $V_{\mathrm{E}}^{\prime} / V^{\prime} \mathrm{CO}_{2}$ slope and its prognostic utility are more flexible than peak values. Indeed, in one study the $V_{\mathrm{E}}^{\prime} / V^{\prime} \mathrm{CO}_{2}$ was the only independent correlate of the REVEAL (Registry to Evaluate Early and Long-term PAH Disease Management) registry risk score in multivariate analysis, with a $V_{\mathrm{E}}^{\prime} / V^{\prime} \mathrm{CO}_{2}$ slope cut-off of 40.6 discriminating patients having a high-risk REVEAL score $(\geqslant 10)$ with a sensitivity of $92 \%$ and specificity of 67\% [95]. It remains unclear whether CPET variables, including $V_{E}^{\prime} / V^{\prime} \mathrm{CO}_{2}$, add prognostic value beyond the REVEAL risk score. Although $V_{\mathrm{E}}^{\prime} / V^{\prime} \mathrm{CO}_{2}$ at baseline was predictive of survival and PAH-targeted treatments seemed to improve $V_{\mathrm{E}}^{\prime} / V^{\prime} \mathrm{CO}_{2}$, treatment-related changes in $V^{\prime}{ }^{\prime} / V^{\prime} \mathrm{CO}_{2}$ slope were not predictive of survival in one study [96].

A key message in recent guidelines and prognostic studies is that risk assessment should be multidimensional and serial over time. Although several of the studies discussed above show that high $V_{\mathrm{E}}^{\prime} / V^{\prime} \mathrm{CO}_{2}$ is a marker of poor prognosis, a pivotal question is whether $V_{\mathrm{E}}^{\prime} / V^{\prime} \mathrm{CO}_{2}$ adds value to other widely used methods such as echocardiography or invasive haemodynamics. BADAGLIACCA et al. prospectively studied the degree of additive benefit of CPET and echocardiography for prognostication in addition to demographic, clinical, haemodynamic and functional class details [97]. The only variables that improved prediction of clinical worsening were peak $\mathrm{O}_{2}$ pulse and RV fractional area change. Others have also demonstrated that while $V_{\mathrm{E}}^{\prime} / V^{\prime} \mathrm{CO}_{2}$ slope as well as $V_{\mathrm{E}}^{\prime} / V_{\mathrm{CO}_{2}}^{\prime}$ peak were associated with survival, once multivariate regression was performed, only $\Delta \mathrm{O}_{2}$ pulse added prognostic value [98]. Haemodynamic variables such as PVR and those that reflect RV function (cardiac output, stroke volume, RAP) are also important predictors of prognosis in PAH [32, 99-101]. WenSEL et al. evaluated the prognostic value of combining CPET-derived values with haemodynamic data from RHC [102]. They assessed several CPET variables, including $V_{\mathrm{E}}^{\prime} / V_{\mathrm{CO}_{2}}^{\prime}$, and found that only peak $V_{\mathrm{O}_{2}}^{\prime}$, PVR and heart rate change during exercise were independently associated with survival. Similarly, another study by BADAGLIACCA et al. found that the only CPET parameter independently associated with future clinical worsening was peak $V_{\mathrm{O}_{2}}^{\prime}$, while $V_{\mathrm{E}}^{\prime} V_{\mathrm{CO}_{2}}^{\prime}$ did not give additional prognostic information [103].

In summary, there is good evidence that CPET variables, including $V_{\mathrm{E}}^{\prime} / V^{\prime} \mathrm{CO}_{2}$, can be used to measure disease severity and are predictive of survival and time to clinical worsening. However, the utility of $V^{\prime}{ }_{\mathrm{E}} / V^{\prime} \mathrm{CO}_{2}$ beyond standard multidimensional prognostication tools requires further investigation.

Conclusion

CPET is a useful tool in the differential diagnosis of dyspnoea. Ventilatory inefficiency during CPET is a hallmark characteristic of PAH and CTEPH which contributes to exercise intolerance and disability in these patients. The mechanisms of ventilatory inefficiency are multiple and include high physiologic dead space, abnormal chemosensitivity and an altered $P_{\mathrm{aCO}}$ set-point. While normal $V_{\mathrm{E}}^{\prime} / V^{\prime} \mathrm{CO}_{2}$ makes pulmonary vascular disease unlikely, the finding of high $V_{E}^{\prime} / V^{\prime} \mathrm{CO}_{2}$ without an alternative explanation should prompt further diagnostic testing to exclude $\mathrm{PAH}$ and $\mathrm{CTEPH}$, particularly in patients with risk factors such as prior venous thromboembolism, systemic sclerosis or a family history. In patients with established PAH or CTEPH, the 
$V_{E}^{\prime} / V_{\mathrm{CO}_{2}}^{\prime}$ may improve with treatments and is a prognostic marker. Further studies are needed to clarify the added value of assessing ventilatory inefficiency in the longitudinal follow-up of patients.

Previous articles in this series: No. 1: Laveneziana P, Di Paolo M, Palange P. The clinical value of cardiopulmonary exercise testing in the modern era. Eur Respir Rev 2021; 30: 200187. No. 2: Agnostoni P, Sciomer S, Palermo P, et al. Minute ventilation/carbon dioxide production in chronic heart failure. Eur Respir Rev 2021; 30: 200141. No. 3: Watson M, Ionescu MF, Sylvester K, et al. Minute ventilation/carbon dioxide production in patients with dysfunctional breathing. Eur Respir Rev 2021; 30: 200182. No. 4: Ward SA. Ventilation/carbon dioxide output relationships during exercise in health. Eur Respir Rev 2021; 30: 200160. No. 5: Collins SÉ, Phillips DB, Brotto AR, et al. Ventilatory efficiency in athletes, asthma and obesity. Eur Respir Rev 2021; 30: 200206. No. 6: Schaeffer MR, Guenette JA, Jensen D. Impact of ageing and pregnancy on the minute ventilation/carbon dioxide production response to exercise. Eur Respir Rev 2021; 30: 200225.

Provenance: Commissioned article, peer reviewed.

Conflict of interest: J. Weatherald reports grants, personal fees and non-financial support from Janssen Inc. and Actelion; personal fees and non-financial support from Bayer; and personal fees from Novartis, outside the submitted work. B. Philipenko has nothing to disclose. D. Montani reports grants and personal fees from Actelion and Bayer; personal fees from GSK, Pfizer, Chiesi and Boerhinger; grants, personal fees and non-financial support from MSD; and non-financial support from Acceleron, outside the submitted work. P. Laveneziana reports personal fees from Novartis France, Boehringer France and Chiesi France, outside the submitted work.

\section{References}

1 Simonneau G, Montani D, Celermajer DS, et al. Haemodynamic definitions and updated clinical classification of pulmonary hypertension. Eur Respir J 2019; 53: 1801913.

2 Humbert M, Guignabert C, Bonnet S, et al. Pathology and pathobiology of pulmonary hypertension: state of the art and research perspectives. Eur Respir J 2019; 53: 1801887.

3 Vonk Noordegraaf A, Chin KM, Haddad F, et al. Pathophysiology of the right ventricle and of the pulmonary circulation in pulmonary hypertension: an update. Eur Respir J 2019; 53: 1801900.

4 Simonneau G, Torbicki A, Dorfmüller P, et al. The pathophysiology of chronic thromboembolic pulmonary hypertension. Eur Respir Rev 2017; 26: 160112.

5 Ende-Verhaar YM, Cannegieter SC, Vonk Noordegraaf A, et al. Incidence of chronic thromboembolic pulmonary hypertension after acute pulmonary embolism: a contemporary view of the published literature. Eur Respir J 2017; 49: 1601792.

6 Weatherald J, Farina S, Bruno N, et al. Cardiopulmonary exercise testing in pulmonary hypertension. Ann Am Thorac Soc 2017; 14: S84-S92.

7 Vallerand JR, Weatherald J, Laveneziana P. Pulmonary hypertension and exercise. Clin Chest Med 2019; 40: 459-469.

8 Farina S, Correale M, Bruno N, et al. The role of cardiopulmonary exercise tests in pulmonary arterial hypertension. Eur Respir Rev 2018; 27: 170134.

9 Weatherald J, Sattler C, Garcia G, et al. Ventilatory response to exercise in cardiopulmonary disease: the role of chemosensitivity and dead space. Eur Respir J 2018; 51: 1700860.

10 Nicolò A, Marcora SM, Sacchetti M. Time to reconsider how ventilation is regulated above the respiratory compensation point during incremental exercise. J Appl Physiol 2020; 128: 1447-1449.

11 Wasserman K, Hansen JE, Sietsema KE, et al. Principles of Exercise Testing and Interpretation: Including Pathophysiology and Clinical Applications. 5th, revised Edn. Philadelphia, Wolters Kluwer Health, 2015.

12 Wasserman K, Van Kessel AL, Burton GG. Interaction of physiological mechanisms during exercise. J Appl Physiol 1967; 22: 71-85.

13 Sun X-G, Hansen JE, Garatachea N, et al. Ventilatory efficiency during exercise in healthy subjects. Am J Respir Crit Care Med 2002; 166: 1443-1448.

14 Habedank D, Reindl I, Vietzke G, et al. Ventilatory efficiency and exercise tolerance in 101 healthy volunteers. Eur J Appl Physiol Occup Physiol 1998; 77: 421-426.

15 Weatherald J, Laveneziana P. Patterns of cardiopulmonary response to exercise in pulmonary vascular diseases. In: Palange P, Laveneziana P, Neder JA, eds, et al. Clinical Exercise Testing (ERS Monograph). Sheffield, European Respiratory Society, 2018; pp. 160-174.

16 Dantzker DR, Bower JS. Mechanisms of gas exchange abnormality in patients with chronic obliterative pulmonary vascular disease. J Clin Invest 1979; 64: 1050-1055.

17 Dantzker DR, D’Alonzo GE. Pulmonary gas exchange and exercise performance in pulmonary hypertension. Chest 1985; 88: 255S-257S. 
Dantzker DR, Bower JS. Pulmonary vascular tone improves VA/Q matching in obliterative pulmonary hypertension. J Appl Physiol Respir Environ Exerc Physiol 1981; 51: 607-613.

Theodore J, Robin ED, Morris AJ, et al. Augmented ventilatory response to exercise in pulmonary hypertension. Chest 1986; 89: 39-44.

Ting $\mathrm{H}$, Sun XG, Chuang ML, et al. A noninvasive assessment of pulmonary perfusion abnormality in patients with primary pulmonary hypertension. Chest 2001; 119: 824-832.

Hoeper MM, Pletz MW, Golpon H, et al. Prognostic value of blood gas analyses in patients with idiopathic pulmonary arterial hypertension. Eur Respir J 2007; 29: 944-950.

Weatherald J, Boucly A, Montani D, et al. Gas exchange and ventilatory efficiency during exercise in pulmonary vascular diseases. Arch Bronconeumol 2020; 56: 578-585.

Laveneziana P, Garcia G, Joureau B, et al. Dynamic respiratory mechanics and exertional dyspnoea in pulmonary arterial hypertension. Eur Respir J 2013; 41: 578-587.

Farina S, Bruno N, Agalbato $\mathrm{C}$, et al. Physiological insights of exercise hyperventilation in arterial and chronic thromboembolic pulmonary hypertension. Int J Cardiol 2018; 259: 178-182.

Naeije R, van de Borne P. Clinical relevance of autonomic nervous system disturbances in pulmonary arterial hypertension. Eur Respir J 2009; 34: 792-794.

Velez-Roa S, Ciarka A, Najem B, et al. Increased sympathetic nerve activity in pulmonary artery hypertension. Circulation 2004; 110: 1308-1312.

McGowan CL, Swiston JS, Notarius CF, et al. Discordance between microneurographic and heart-rate spectral indices of sympathetic activity in pulmonary arterial hypertension. Heart 2009; 95: 754-758.

Ciarka A, Doan V, Velez-Roa S, et al. Prognostic significance of sympathetic nervous system activation in pulmonary arterial hypertension. Am J Respir Crit Care Med 2010; 181: 1269-1275.

Wensel R, Jilek C, Dörr M, et al. Impaired cardiac autonomic control relates to disease severity in pulmonary hypertension. Eur Respir J 2009; 34: 895-901.

Dimopoulos S, Anastasiou-Nana M, Katsaros F, et al. Impairment of autonomic nervous system activity in patients with pulmonary arterial hypertension: a case control study. J Card Fail 2009; 15: 882-889.

Ciarka A, Vachièry J-L, Houssière A, et al. Atrial septostomy decreases sympathetic overactivity in pulmonary arterial hypertension. Chest 2007; 131: 1831-1837.

Weatherald J, Boucly A, Chemla D, et al. Prognostic value of follow-up hemodynamic variables after initial management in pulmonary arterial hypertension. Circulation 2018; 137: 693-704.

Rehman MB, Howard LS, Christiaens LP, et al. Resting right ventricular function is associated with exercise performance in PAH, but not in CTEPH. Eur Heart J Cardiovasc Imaging 2018; 19: 185-192.

Zhai Z, Murphy $\mathrm{K}$, Tighe $\mathrm{H}$, et al. Differences in ventilatory inefficiency between pulmonary arterial hypertension and chronic thromboembolic pulmonary hypertension. Chest 2011; 140: 1284-1291.

Godinas L, Sattler C, Lau EM, et al. Dead-space ventilation is linked to exercise capacity and survival in distal chronic thromboembolic pulmonary hypertension. J Heart Lung Transplant 2017; 36: 1234-1242.

Neder JA, Arbex FF, Alencar MCN, et al. Exercise ventilatory inefficiency in mild to end-stage COPD. Eur Respir J 2015; 45: 377-387.

Apostolo A, Laveneziana $\mathrm{P}$, Palange $\mathrm{P}$, et al. Impact of chronic obstructive pulmonary disease on exercise ventilatory efficiency in heart failure. Int J Cardiol 2015; 189: 134-140.

Boucly A, Morélot-Panzini C, Garcia G, et al. Intensity and quality of exertional dyspnoea in patients with stable pulmonary hypertension. Eur Respir J 2020; 55: 1802108.

Sun XG, Hansen JE, Oudiz RJ, et al. Exercise pathophysiology in patients with primary pulmonary hypertension. Circulation 2001; 104: 429-435.

Dumitrescu D, Nagel C, Kovacs G, et al. Cardiopulmonary exercise testing for detecting pulmonary arterial hypertension in systemic sclerosis. Heart 2017; 103: 774-782.

Coghlan JG, Denton CP, Grünig E, et al. Evidence-based detection of pulmonary arterial hypertension in systemic sclerosis: the DETECT study. Ann Rheum Dis 2014; 73: 1340-1349.

Santaniello A, Casella R, Vicenzi M, et al. Cardiopulmonary exercise testing in a combined screening approach to individuate pulmonary arterial hypertension in systemic sclerosis. Rheumatology (Oxford) 2020; 59: 1581-1586.

Girerd B, Montani D, Jaïs X, et al. Genetic counselling in a national referral centre for pulmonary hypertension. Eur Respir J 2016; 47: 541-552.

Girerd B, Weatherald J, Montani D, et al. Heritable pulmonary hypertension: from bench to bedside. Eur Respir Rev 2017; 26: 170037.

Bhatti YJ, Rice AJ, Kempny A, et al. Early histological changes of pulmonary arterial hypertension disclosed by invasive cardiopulmonary exercise testing. Pulm Circ 2019; 9: 2045894019845615.

Trip P, Vonk-Noordegraaf A, Bogaard HJ. Cardiopulmonary exercise testing reveals onset of disease and response to treatment in a case of heritable pulmonary arterial hypertension. Pulm Circ 2012; 2: 387-389.

Montani D, Girerd B, Jaïs X, et al. Screening for pulmonary arterial hypertension in adults carrying a BMPR2 mutation. Eur Respir J 2020; in press [DOI: 10.1183/13993003.04229-2020] 
Weber KT, Kinasewitz GT, Janicki JS, et al. Oxygen utilization and ventilation during exercise in patients with chronic cardiac failure. Circulation 1982; 65: 1213-1223.

Wasserman K, Zhang YY, Gitt A, et al. Lung function and exercise gas exchange in chronic heart failure. Circulation 1997; 96: 2221-2227.

Deboeck G, Niset G, Lamotte M, et al. Exercise testing in pulmonary arterial hypertension and in chronic heart failure. Eur Respir J 2004; 23: 747-751.

Nishio R, Tanaka H, Tsuboi Y, et al. Differences in hemodynamic parameters and exercise capacity between patients with pulmonary arterial hypertension and chronic heart failure. J Cardiopulm Rehabil Prev 2012; 32: 379-385.

Liu W-H, Luo Q, Liu Z-H, et al. Pulmonary function differences in patients with chronic right heart failure secondary to pulmonary arterial hypertension and chronic left heart failure. Med Sci Monit 2014; 20: 960-966.

Vicenzi M, Deboeck G, Faoro V, et al. Exercise oscillatory ventilation in heart failure and in pulmonary arterial hypertension. Int J Cardiol 2016; 202: 736-740.

Van Iterson EH, Johnson BD, Borlaug BA, et al. Physiological dead space and arterial carbon dioxide contributions to exercise ventilatory inefficiency in patients with reduced or preserved ejection fraction heart failure. Eur J Heart Fail 2017; 19: 1675-1685.

Maeder MT, Thompson BR, Htun N, et al. Hemodynamic determinants of the abnormal cardiopulmonary exercise response in heart failure with preserved left ventricular ejection fraction. $J$ Card Fail 2012; 18: 702-710.

Smith JR, Borlaug BA, Olson TP. Exercise ventilatory efficiency in older and younger heart failure patients with preserved ejection fraction. J Card Fail 2019; 25: 278-285.

Reddy YNV, Olson TP, Obokata M, et al. Hemodynamic correlates and diagnostic role of cardiopulmonary exercise testing in heart failure with preserved ejection fraction. JACC Heart Fail 2018; 6: 665-675.

Ho JE, Zern EK, Wooster L, et al. Differential clinical profiles, exercise responses, and outcomes associated with existing HFpEF definitions. Circulation 2019; 140: 353-365.

Wensel R, Opitz CF, Anker SD, et al. Assessment of survival in patients with primary pulmonary hypertension: importance of cardiopulmonary exercise testing. Circulation 2002; 106: 319-324.

Gorter TM, Obokata M, Reddy YNV, et al. Exercise unmasks distinct pathophysiologic features in heart failure with preserved ejection fraction and pulmonary vascular disease. Eur Heart J 2018; 39: 2825-2835.

Fayyaz AU, Edwards WD, Maleszewski JJ, et al. Global pulmonary vascular remodeling in pulmonary hypertension associated with heart failure and preserved or reduced ejection fraction. Circulation 2018; 137: 1796-1810.

Klaassen SHC, Liu LCY, Hummel YM, et al. Clinical and hemodynamic correlates and prognostic value of VE/ $\mathrm{VCO}_{2}$ slope in patients with heart failure with preserved ejection fraction and pulmonary hypertension. J Card Fail 2017; 23: 777-782.

Scheidl SJ, Englisch C, Kovacs G, et al. Diagnosis of CTEPH versus IPAH using capillary to end-tidal carbon dioxide gradients. Eur Respir J 2012; 39: 119-124.

Akizuki M, Sugimura K, Aoki T, et al. Non-invasive screening using ventilatory gas analysis to distinguish between chronic thromboembolic pulmonary hypertension and pulmonary arterial hypertension. Respirology 2020; 25: 427-434.

Galiè N, Humbert M, Vachiery J-L, et al. 2015 ESC/ERS Guidelines for the diagnosis and treatment of pulmonary hypertension. Eur Respir J 2015; 46: 903-975.

Xi Q, Zhao Z, Liu Z, et al. The lowest $\mathrm{VE} / \mathrm{VCO}_{2}$ ratio best identifies chronic thromboembolic pulmonary hypertension. Thromb Res 2014; 134: 1208-1213.

McCabe C, Deboeck G, Harvey I, et al. Inefficient exercise gas exchange identifies pulmonary hypertension in chronic thromboembolic obstruction following pulmonary embolism. Thromb Res 2013; 132: 659-665.

Held M, Grün M, Holl R, et al. Cardiopulmonary exercise testing to detect chronic thromboembolic pulmonary hypertension in patients with normal echocardiography. Respiration 2014; 87: 379-387.

Weatherald J, Dorfmüller P, Perros F, et al. Pulmonary capillary haemangiomatosis: a distinct entity? Eur Respir Rev 2020; 29: 190168.

Humbert M, Maître S, Capron F, et al. Pulmonary edema complicating continuous intravenous prostacyclin in pulmonary capillary hemangiomatosis. Am J Respir Crit Care Med 1998; 157: 1681-1685.

Montani D, Girerd B, Jaïs X, et al. Clinical phenotypes and outcomes of heritable and
veno-occlusive disease: a population-based study. Lancet Respir Med 2017; 5: 125-134.

2 Laveneziana $\mathrm{P}$, Montani D, Dorfmüller $\mathrm{P}$, et al. Mechanisms of exertional dyspnoea in pulmonary veno-occlusive disease with EIF2AK4 mutations. Eur Respir J 2014; 44: 1069-1072.

Riley MS, Pórszász J, Engelen MP, et al. Responses to constant work rate bicycle ergometry exercise in primary pulmonary hypertension: the effect of inhaled nitric oxide. J Am Coll Cardiol 2000; 36: 547-556.

Nagaya N, Uematsu M, Oya H, et al. Short-term oral administration of L-arginine improves hemodynamics and exercise capacity in patients with precapillary pulmonary hypertension. Am J Respir Crit Care Med 2001; 163: 887-891. 
Nagaya N, Shimizu Y, Satoh T, et al. Oral beraprost sodium improves exercise capacity and ventilatory efficiency in patients with primary or thromboembolic pulmonary hypertension. Heart 2002; 87: 340-345.

Ulrich S, Hasler ED, Saxer S, et al. Effect of breathing oxygen-enriched air on exercise performance in patients with precapillary pulmonary hypertension: randomized, sham-controlled cross-over trial. Eur Heart J 2017; 38: 1159-1168.

Kim NH, Delcroix M, Jais X, et al. Chronic thromboembolic pulmonary hypertension. Eur Respir J 2019; 53: 1801915.

Thistlethwaite PA, Kaneko K, Madani MM, et al. Technique and outcomes of pulmonary endarterectomy surgery. Ann Thorac Cardiovasc Surg 2008; 14: 274-282.

Iwase T, Nagaya N, Ando M, et al. Acute and chronic effects of surgical thromboendarterectomy on exercise capacity and ventilatory efficiency in patients with chronic thromboembolic pulmonary hypertension. Heart 2001; 86: 188-192.

van Kan C, van der Plas MN, Reesink HJ, et al. Hemodynamic and ventilatory responses during exercise in chronic thromboembolic disease. J Thorac Cardiovasc Surg 2016; 152: 763-771.

Guth S, Wiedenroth $\mathrm{CB}$, Rieth $\mathrm{A}$, et al. Exercise right heart catheterisation before and after pulmonary endarterectomy in patients with chronic thromboembolic disease. Eur Respir J 2018; 52: 1800458.

Lang I, Meyer BC, Ogo T, et al. Balloon pulmonary angioplasty in chronic thromboembolic pulmonary hypertension. Eur Respir Rev 2017; 26: 160119.

Fukui S, Ogo T, Goto Y, et al. Exercise intolerance and ventilatory inefficiency improve early after balloon pulmonary angioplasty in patients with inoperable chronic thromboembolic pulmonary hypertension. Int $J$ Cardiol 2015; 180: 66-68.

Andreassen AK, Ragnarsson A, Gude E, et al. Balloon pulmonary angioplasty in patients with inoperable chronic thromboembolic pulmonary hypertension. Heart 2013; 99: 1415-1420.

Akizuki M, Serizawa N, Ueno A, et al. Effect of balloon pulmonary angioplasty on respiratory function in patients with chronic thromboembolic pulmonary hypertension. Chest 2017; 151: 643-649.

, Extensive revascularisation by balloon pulmonary angioplasty for chronic thromboembolic pulmonary hypertension beyond haemodynamic normalisation. Eurolntervention 2018; 13: 2060-2068.

Hoole SP, Coghlan JG, Cannon JE, et al. Balloon pulmonary angioplasty for inoperable chronic thromboembolic pulmonary hypertension: the UK experience. Open Heart 2020; 7: e001144.

Fukui S, Ogo T, Takaki H, et al. Efficacy of cardiac rehabilitation after balloon pulmonary angioplasty for chronic thromboembolic pulmonary hypertension. Heart 2016; 102: 1403-1409.

Schwaiblmair M, Faul C, von Scheidt W, et al. Ventilatory efficiency testing as prognostic value in patients with pulmonary hypertension. BMC Pulm Med 2012; 12: 23.

Oudiz RJ, Midde R, Hovenesyan A, et al. Usefulness of right-to-left shunting and poor exercise gas exchange for predicting prognosis in patients with pulmonary arterial hypertension. Am J Cardiol 2010; 105: 1186-1191.

1 Deboeck G, Scoditti C, Huez S, et al. Exercise testing to predict outcome in idiopathic versus associated pulmonary arterial hypertension. Eur Respir J 2012; 40: 1410-1419.

Ewert R, Ittermann T, Habedank D, et al. Prognostic value of cardiopulmonary exercise testing in patients with systemic sclerosis. BMC Pulm Med 2019; 19: 230.

Dimopoulos K, Okonko DO, Diller G-P, et al. Abnormal ventilatory response to exercise in adults with congenital heart disease relates to cyanosis and predicts survival. Circulation 2006; 113: 2796-2802.

Ferreira EVM, Ota-Arakaki JS, Ramos RP, et al. Optimizing the evaluation of excess exercise ventilation for prognosis assessment in pulmonary arterial hypertension. Eur J Prev Cardiol 2014; 21: 1409-1419.

Khatri V, Neal JE, Burger CD, et al. Prognostication in pulmonary arterial hypertension with submaximal exercise testing. Diseases 2015; 3: 15-23.

Groepenhoff $\mathrm{H}$, Vonk-Noordegraaf A, van de Veerdonk MC, et al. Prognostic relevance of changes in exercise test variables in pulmonary arterial hypertension. PLoS One 2013; 8: e72013.

Badagliacca R, Papa S, Valli G, et al. Echocardiography combined with cardiopulmonary exercise testing for the prediction of outcome in idiopathic pulmonary arterial hypertension. Chest 2016; 150: 1313-1322.

Groepenhoff $\mathrm{H}$, Vonk-Noordegraaf A, Boonstra A, et al. Exercise testing to estimate survival in pulmonary hypertension. Med Sci Sports Exerc 2008; 40: 1725-1732.

Weatherald J, Boucly A, Launay D, et al. Haemodynamics and serial risk assessment in systemic sclerosis associated pulmonary arterial hypertension. Eur Respir J 2018; 52: 1800678.

Saggar R, Sitbon O. Hemodynamics in pulmonary arterial hypertension: current and future perspectives. Am J Cardiol 2012; 110: S9-S15.

Benza RL, Gomberg-Maitland M, Elliott CG, et al. Predicting survival in patients with pulmonary arterial hypertension: the REVEAL Risk Score Calculator 2.0 and comparison with ESC/ERS-based risk assessment strategies. Chest 2019; 156: 323-337. 
102 Wensel R, Francis DP, Meyer FJ, et al. Incremental prognostic value of cardiopulmonary exercise testing and resting haemodynamics in pulmonary arterial hypertension. Int J Cardiol 2013; 167: 1193-1198.

103 Badagliacca R, Papa S, Poscia R, et al. The added value of cardiopulmonary exercise testing in the follow-up of pulmonary arterial hypertension. J Heart Lung Transplant 2019; 38: 306-314. 